\title{
Interconnectedness in Credit Market: An Empirical Investigation Using UK and US CDS Data
}

\author{
Ramaprasad Bhar Ph.D \\ School of Risk and Actuarial Studies, University of New South Wales, Australia
}

\begin{abstract}
This paper uses a structural time series methodology to test the notion of interconnectedness between the UK and the US credit markets. The empirical tests utilise data on premium for the Banking sector credit default swaps (CDS) and covers the recent period of financial turmoil. The methodology based on Kalman filter is robust in the presence of limited convergence. The long-term steady state convergence in CDS premium is clearly noticeable between these two markets from the results. This observation lends support for the coordinated regulatory policy initiatives to deal with the crisis and offer suggestions for sound operations of the international financial systems.
\end{abstract}

Key words: Banking Sector, CDS, Convergence, Kalman filter

\section{Introduction}

The world has experienced financial turmoil of unprecedented proportions over the last few years. It was preceded by a long period of abundant liquidity, rising asset prices and low interest rates. In the context of international financial integration and innovation this led to the build-up of global macroeconomic imbalances as well as a global "search-for-yield" and general underpricing of risk by investors. Regulators in some cases facilitated, and in other cases failed to respond to the build-up in imbalances. The plentiful liquidity induced a rapid expansion of credit in many developed and emerging countries. Mortgage finance was one of the high growth areas, both in the US and elsewhere, and contributed to a bubble in global real estate prices.

Financial innovation at the same time increased systemic vulnerability in a number of ways. The growth of the mortgage market, especially in the US, was supported by financial innovation in credit derivatives as well as by an active secondary market for mortgage-related securities. Moreover, both regulated and unregulated financial institutions became more 'interconnected' via over the counter markets with bilateral clearing and settlement arrangements. At the same time, the favourable macroeconomic environment, increased competition, technological advances, and growing asset prices caused financial institutions to move down-market, to lower credit underwriting standards, to engage in riskier trading activities with maturity mismatches and to rely excessively on quantitative risk models.

Given the role played by the financial institutions and the consequences of the financial crisis across the advanced economies, this paper is motivated to examine the dynamic behaviour of the Banking sector indices for the CDS (Credit Default Swaps) spread (expressed in basis points) for two OECD economies. Agreed, that both the US and the UK have large banking sector and their 
Interconnectedness in Credit Market

relative importance to the respective economies, we examine whether the perceived riskiness of this sector was converging over time. We use the CDS premium as the measure of sector riskiness as perceived by the market.

A CDS index is a highly liquid, standardized credit security that trades at a very small bidask spread. CDS's can be efficient in processing information on evolving risks in the financial sectors and the rest of the economy (see Norden and Weber, 2004; and Greatrex, 2008, among others). On the other hand, CDS's can feed on negative financial news and promote speculations and may have contributed to the financial crisis (Stulz, 2010). They may also alter the debtorcreditor relation in the event of financial distress such as the recent financial crisis (Bolton and Oehmke, 2011). They may create empty creditors-holders of debt and CDS-who no longer have an interest in the efficient continuation of the debtor, and who may push the debtor into inefficient bankruptcy or liquidation. Ashcraft, Joao and Santos (2009) fail to find evidence that CDS trading lowers the cost of debt financing for the average borrower, as some have argued. Therefore, many politicians and analysts want these CDS contracts to trade on organised exchanges and go through the usual clearinghouses and have international standardization.

Since the magnitude of the financial credit spreads gauges the default risk exposure of the institutions that make up the financial sectors, a widening of CDS spread in response to certain credit events indicates an increase in the level of credit risk in the pertinent economic sector, while a narrowing in the spread would indicate the opposite.

It is also known in the literature that the CDS spreads include several components related to default risk, expected loss and liquidity premium. In contrast the bond spreads have dependency on non-default components (see, e.g. Ericsson, Reneby and Wang, 2006). Thus, this paper is also motivated by the recent elevations of risks to focus on the sensitivity of the banking sectors' CDS spreads to default risk, banking risk premium, banking liquidity premium. The interconnectedness of the banking sector CDS spreads would thus indicate correspondence in the components of these risk premia of the two economies.

Banks receive deposits and specialize in making loans. This basic nature is not much different in both these economies. The buying and selling activities in the CDS market would contain information of the perceived riskiness in this sector. Some banks tie the prices of their syndicated loans to corporations to the borrowers' CDS spreads. Rising CDS spreads should reinforce the march toward higher risk in the economic sectors and induce an emigration of risk towards the safer contracts. In sum, all the CDS spreads gauge the health of the economy.

The literature has just begun to focus on comovement of risks during the 2009 financial crisis. It's also premature to say the literature has given adequate consideration of the impacts of the recent quantitative easing $(\mathrm{QE})$ on risk elevation and migration, while our study has. The paper is also motivated by this research gap in the literature regarding the interconnectedness between the same sectors of the economies bound by many similarities.

The broad objective of the paper is to discern whether the riskiness of the banking sector as a whole for the two economies was converging during the period that spans the global financial crisis period. The results should be helpful in providing strategy implications for traders and hedgers who may be operating in both these markets. The results should also have policy 
implications for regulatory authorities with emphasis on the contagion effect, particularly the shocks originating from the banking sector. CDS data from other industries may also be examined in such an analysis. However, the focus on the banking sector is simply because this sector is the origin of financial crisis.

As a result of the crisis some of the largest and most respected banks, investment houses, and insurance companies have either declared bankruptcy or have had to be rescued financially. Nearly all industrialized countries announced economic stimulus and/or financial sector rescue packages. Several countries resorted to borrowing from the International Monetary Fund as a last resort. The crisis has exposed fundamental weaknesses in financial systems worldwide, demonstrated how interconnected and interdependent economies are today, and has posed vexing policy dilemmas.

The process for coping with the crisis by countries across the globe has involved government intervention and changes in the financial system to reduce risk and prevent future crises. The crisis has reaffirmed some fundamental tenets of banking sector policymaking, such as the need for a solid financial infrastructure, including sound accounting and auditing standards, effective collateral registration and enforcement systems, well-functioning payments and settlement systems, and well-designed corporate governance structures. At the same time, the crisis is also prompting a reconsideration of certain elements of financial sector policymaking, including regulation and supervision (Nanto, 2009). The proposed regulatory changes will need to be coordinated among nations to avoid migration of business and transactions to less regulated markets. If regulations in certain countries are anomalous or significantly more "burdensome" than those in other industrialized nations, business and transactions could migrate toward other markets.

In this paper we show that due to the relatively strong interconnectedness of the banking sector in the UK and the US, the sustainability and effectiveness of the global economy is dependent upon the introduction of a uniform finance architecture guided by global policy frameworks. The focus on these two markets originates from observation in the IMF report (Chan-Lau, Mitra, and Ong (2007)) that "On a country-by-country basis, U.K.-owned banks' biggest exposures are to the United States" on page 8. Besides, due to historical and cultural linkages between these two developed financial sectors would make them suitable candidates for this exploratory analysis. However, we recognise the uniqueness of economies and the significance of local market knowledge and suggest discretionary application of the proposed global policy measures by sovereign governments on a national level.

\section{Literature Review}

Financial researchers have vastly explored the topic of financial markets integration over the past three decades. Diverse methodologies and databases have been used to study the this area of interest, however, most have taken the common approach of modelling return series from similar asset markets and analysing feedback mechanisms through the first or the second moments of the distributions. Malliaris and Urrutia $(1992,1997)$ show that certain global events 
tend to move national stock markets in unison. McCarthy and Najand (1995) also provide a good account of the literature in stock market linkages.

Merton (1980) provides the basis for an alternative approach to the analyses of the stock market risk premium. Merton's model of inter-temporal capital asset pricing demonstrates that a risk-averse investor demands a risk premium to compensate for the market risk. Assuming that the variance of the market return is a sufficient statistic for the market risk, this risk premium is proportional to the market return. In the case of a representative investor, this proportionality constant is also equal to the investor's relative risk aversion. This multiplier can also be used to measure risk by providing the unit price of risk. There is no evidence to suggest that the unit price of risk should remain constant over time. This, in fact, is the approach adopted by Jochum (1999) and shows that the time variation in the price of risk can be estimated using an unobserved component model.

The notion of time variation of the unit price of risk is by no means limited to the framework outlined above. The derivative contracts written on the market indices of many countries offer another potential source of data for inferring the time variation of the market price of risk. The concept is embedded in the rich theory of derivatives pricing, a theory which requires a relation between risk-neutrality and historical probability distributions. Bhar et al. (2004) demonstrate how the model can be set-up in the state space framework to infer the time variation of the market price of risk quite efficiently.

The above strategies relate to the measurement of price of risk in the equity market. However, we intend to focus on pricing of risk in the credit market. The standard way of evaluating changes in markets' perceived credit outlook for firms is by monitoring movements in corporate bond spreads. These are usually measured as the difference between the yields offered on firms' corporate debt instruments and the risk-free interest rates, the latter is normally approximated by government bond yields. Corporate bond spreads can be defined as the risk premium corporations pay investors to compensate them for a number of risks associated with corporate debt.

Besides, recent financial innovations, in the form of credit derivatives, have provided analysts and policy makers further measures to gauge firms' perceived credit risk. Credit Default Swaps similar to corporate bond spreads, capture credit risk. In a CDS agreement the buyer of protection against default makes a periodic or upfront payment to the seller of the default swap. The seller of protection promises to make a payment in the event of a default on a reference obligation which is usually a bond or a loan. The default swap premium is often referred to as the default swap spread.

Alexopoulou, Andersson and Georgescu (2009) confirm the existence of a long-run relationship between the two markets, and the tendency for CDS markets to lead corporate bond markets in terms of price discovery. They find that the outbreak of the financial turmoil in the summer of 2007 induced a substantial increase in risk aversion and a shift in the pricing of credit risk, with CDS markets becoming more sensitive to systematic risk while cash bond markets priced in more information about liquidity and idiosyncratic risk. Moreover, the financial turbulence also brought about a systematic disconnection between the two markets caused by the significant change in the lead-lag relationship, with CDS markets always leading the cash bond 
markets. In this context, we focus on the CDS market data to analyse convergence in the two OECD credit markets. We will use the terms interconnectedness and convergence transposable.

In addition to the studies of integration, a number of different methods have been proposed to test and measure the convergence of economic series. The main conclusions that arise from some previous work are covered as follows. Some methods use cross-section information when testing for convergence of a group of more than two series. Examples are the analysis of the time series of a dispersion measure, "initial value" or "Barro" regressions and their derivations, random fields regressions and the estimation of Markov transition matrices (St. Aubyn, 1999). These methods suffer from a common drawback: it becomes difficult to accommodate the possibility of limited convergence. By limited convergence it is understood that only a subset of series (e.g. countries' GDPs) converge to one leading series. When there is more than one such grouping, there is more than one leading series and each of the remaining series is attracted by one and only one of them. The methods proposed by Quah (1996) and by Durlauf and Johnson (1992) are specially designed to address this issue. But, their effectiveness relies on strong correlation within the groupings. St. Aubyn (1995) demonstrates this using the Monte Carlo method.

Pure time series tests for convergence usually take the difference between two series and analyze its properties. According to St. Aubyn (1999), they share a common characteristic: they make it possible to allow for convergence clubs or limited convergence. For example, if you suppose that country A belongs to the same club as country B, simply test for convergence of series A to B. The more popular time series approach to convergence is to test this difference for stationarity using, for example, a Dickey-Fuller statistic. This approach is not completely satisfactory, in the sense that convergence, according to the definitions from the previous section, does not necessarily imply stationarity of the differences. For example, Hall, Roberston and Wickens (1992) give the following example: two series are completely independent from each other, and, from a certain point in time, become exactly equal. These series would converge, but would not pass the stationarity test. In order to allow for a convergence process that starts occurring after the beginning of the period being considered, Hall, Roberston and Wickens (1992) propose the use of the Kalman Filter. St. Aubyn (1999) reports evidence that this method is more powerful than the Dickey-Fuller's when there is a structural break in the convergence process.

This paper uses well developed empirical methodology to measure the interconnectedness of the two credit markets - UK and the USA using banking sector CDS indices. The data covers the period 2004 to 2010 and this, obviously, includes the global financial crisis period. We go a step beyond the conventional use of first and second moments of equity return time series, and use the information from the credit derivative market directly. If these two credit markets are financially integrated, the riskiness of these two markets would converge. If these two markets are segmented then the convergence in the CDS time series would not be apparent. More specifically, we apply the Kalman filter convergence tests to the daily CDS index prices to measure the interconnectedness between these countries' credit sectors.

The rest of the paper is organised as follows: section 3 covers the empirical model; section 4 covers the data, section 5 presents the empirical results and section 6 concludes. 


\section{Expirical model}

\subsection{Defining Convergence}

The meaning of convergence may be clarified before we proceed into testing for it. We are considering two economic series of interest to us. For example, these could be GDPs per head of any two countries. These two are said to converge to each other if their difference becomes stationary in the long term. In more formal terms, consider two economic series and. These two may represent GDPs per head or any other two series we are interested in. These two series converge if:

$$
\left(\mathrm{X}_{\mathrm{t}}-\mathrm{Y}_{\mathrm{t}}\right) \stackrel{\mathrm{P}}{\rightarrow} \varepsilon_{\mathrm{t}} \text { as } \mathrm{t} \rightarrow \infty
$$

where $\varepsilon_{\mathrm{t}}$ is a random variable obeying the following conditions:

$$
\mathrm{E}\left[\varepsilon_{\mathrm{t}}\right]=\mathrm{D}_{\mathrm{XY}}, \operatorname{Var}\left(\varepsilon_{\mathrm{t}}\right)=\sigma^{2}<\infty
$$

Equations (1) and (2) mean that the difference between the two series converges in probability to a third series that is stationary, having a constant mean $\mathrm{D}_{\mathrm{XY}}$ and a finite constant variance $\sigma^{2}$.

To turn this definition into one compatible with the definitions presented elsewhere (e.g. Barro and Sala-i-Martin, 1995), we could define economic convergence as:

a) Point wise, if $\sigma^{2}=0$;

b) Unconditional, if $\mathrm{D}_{\mathrm{XY}}=0$;

c) Conditional, if $\mathrm{D}_{\mathrm{XY}} \neq 0$.

Thus, the above definitions encompass the "beta-convergence" concept proposed by Barro and Sala-i-Martin (1995). In their study, series are supposed to converge to their steady-state level at an annual constant rate. If steady-states are the same, "beta-convergence" is unconditional. If they are different but grow at the same rate, "beta-convergence" is conditional. Definitions presented in (1) and (2) are more general because they do not imply a constant rate of convergence and therefore differences between series are not necessarily stationary from the beginning.

Bernard and Durlauf (1995) propose a related definition: series and converge if the long run forecasts for both series are equal at time $t$ :

$$
\operatorname{Lim}_{k \rightarrow \infty}\left(X_{t+k}-Y_{t+k} \mid I_{t}\right)=0
$$

where $I_{t}$ represents information at time $t$. 
In some sense, the definition in (3) is more stringent: Bernard and Durlauf actually allows for the difference between series to be a random walk. The definition in (4) and (5) prevents this possibility by imposing a restriction on the variance.

\subsection{Testing for Convergence}

\subsubsection{Testing Convergence - Dickey-Fuller}

Dickey-Fuller convergence tests are stationarity tests for the differences between the two economic series. Equation (4) can be estimated using OLS and $d_{t}$ is the difference between the two series being discussed.

$$
\mathrm{d}_{\mathrm{t}}-\mathrm{d}_{\mathrm{t}-1}=\mathrm{b}_{1}+\mathrm{b}_{2} \mathrm{~d}_{\mathrm{t}-1}+\sum_{\mathrm{j}=1}^{1} \mathrm{~b}_{2+\mathrm{j}}\left(\mathrm{d}_{\mathrm{t}-\mathrm{j}}-\mathrm{d}_{\mathrm{t}-\mathrm{j}-1}\right)+\varepsilon_{\mathrm{t}}
$$

The number of lags denoted by is chosen so that the residuals would not display significant autocorrelation or non-normality. The standard tests for autocorrelation and normality could be implemented for this purpose.

The statistic of concern is the t-statistic for the coefficient. Under the null hypothesis of nonstationary, this statistic is not normally distributed. The relevant critical values are available from MacKinnon (1991).

\subsubsection{Testing Convergence - Kalman Filter}

Here is the brief description of the method and the detailed description can be found in St. Aubyn (1995). In this approach the difference between the two series, $\mathrm{d}_{\mathrm{t}}$, is modeled as,

$$
\begin{gathered}
\mathrm{d}_{\mathrm{t}}=\alpha_{\mathrm{t}}+\varepsilon_{\mathrm{t}}, \varepsilon_{\mathrm{t}} \sim \mathrm{N}\left(0, \sigma_{\varepsilon}^{2}\right) \\
\alpha_{\mathrm{t}}=\alpha_{\mathrm{t}-1}+\eta_{\mathrm{t}}, \eta_{\mathrm{t}} \sim \mathrm{N}\left(0, \Omega_{\mathrm{t}}^{2}\right), \Omega_{\mathrm{t}}^{2}=\phi \Omega_{\mathrm{t}-1}^{2}
\end{gathered}
$$

and $\Omega_{0}^{2}$ is the assumed initial value of the variance of $\alpha_{t}$.

The difference between the two series is modeled as a random walk plus noise. Although the noise variance $\sigma_{\varepsilon}^{2}$ is constant through time, the variance of $\eta_{t}$ is potentially time varying and

given by $\Omega_{\mathrm{t}}^{2}$. If $|\phi|$ is less than 1 , this variance tends to 0 in the long run, meaning that the two series are converging. Their difference becoming a stationary variable: the random walk component vanishes eventually and the noise becomes the only stochastic disturbance.

The model in (5) and (6) is written in state-space form equation where the first equation is the measurement equation and the second is the state equation. The likelihood function can be 
constructed using the Kalman Filter as discussed in chapter 8 of Bhar and Hamori (2005). The maximum likelihood estimates for the parameters are obtained by maximizing it.

The null hypothesis of no convergence implies that $\phi=1$. Therefore, the proper test for convergence is: $\mathrm{H}_{0}: \phi=1$ against $\mathrm{H}_{1}: \phi<1$. The implementation of this test requires the distribution of $\phi$ under the null. St. Aubyn (1995) shows via simulation the critical values that are applicable for this hypothesis test. The test is based on the quantity,

$$
\mathrm{t}(\widehat{\phi})=\frac{\widehat{\phi}-1}{\sqrt{\mathrm{h}_{\phi}^{-1}}}
$$

where $\widehat{\phi}$ is the estimated maximum likelihood value of $\phi$ and $\mathrm{h}_{\phi}^{-1}$ is the inverse of the diagonal element of the Hessian matrix corresponding to $\phi$.

The test described above using Kalman Filter can be easily extended to accommodate differences in steady state values reached by the economic time series being investigated. Finally, the hypothesis that there are differences in the convergence process across the candidate series is addressed. That is to say that even if all series are converging towards the same attracting economy, it may well be the case that they are doing it at different speeds and towards different steady-states.

Consider the following set up,

$$
\begin{gathered}
\mathrm{d}_{\mathrm{t}}=\mathrm{d}_{\mathrm{sS}}+\mathrm{b}_{\mathrm{t}}\left(\mathrm{d}_{\mathrm{t}-1}-\mathrm{d}_{\mathrm{SS}}\right)+\varepsilon_{\mathrm{t}} \\
\mathrm{b}_{\mathrm{t}}-\overline{\mathrm{b}}=\mathrm{a}_{1}\left(\mathrm{~b}_{\mathrm{t}-1}-\overline{\mathrm{b}}\right)+\eta_{\mathrm{t}},-1<\mathrm{a}_{1}<1
\end{gathered}
$$

Here, $\varepsilon_{t}$ and $\eta_{t}$ are i.i.d. normally distributed. $b_{t}$ is a time-varying speed of convergence. Since $a_{1}$ is bounded within the unit circle, $b_{t}$ tends to return to its "long run" value, given by $\bar{b}$. This is a case of a "return to normality" model. If $b_{t}$ is smaller than one, the difference between the two series converges to the steady-state value given by $d_{\text {SS }}$.

Equations (8) and (9) express the measurement and transition equations in a state-space representation of the return to normality model. The concentrated log-likelihood can be written, as discussed in chapter 8 of Bhar and Hamori (2005), as an implicit function of the relevant parameters and maximized using numerical methods.

\section{Data}

The model is applied to the banking sector daily CDS quotes for UK and the USA. The period covers beginning January 2004 to end December 2010. This gives us 1827 observations. The 
banking-sector five year CDS premium (mid quote) are obtained from Datastream. The specific Datastream variables used are USBANCD and UKBANCD. The summary statistics for the data used are presented in Table 1.

\begin{tabular}{ccccccc}
\hline \multicolumn{7}{c}{ Summary Statistics } \\
\hline UK & Mean & Std Dev & Max & Min & Skewness & Kurtosis \\
USA & 69.18 & 66.61 & 235.21 & 4.63 & 0.4733 & 1.6766 \\
\hline
\end{tabular}

Table 1: Summary Statistics

In order to get a visual appreciation of the variability of the CDS indexes over the sample period, we include the following plot.

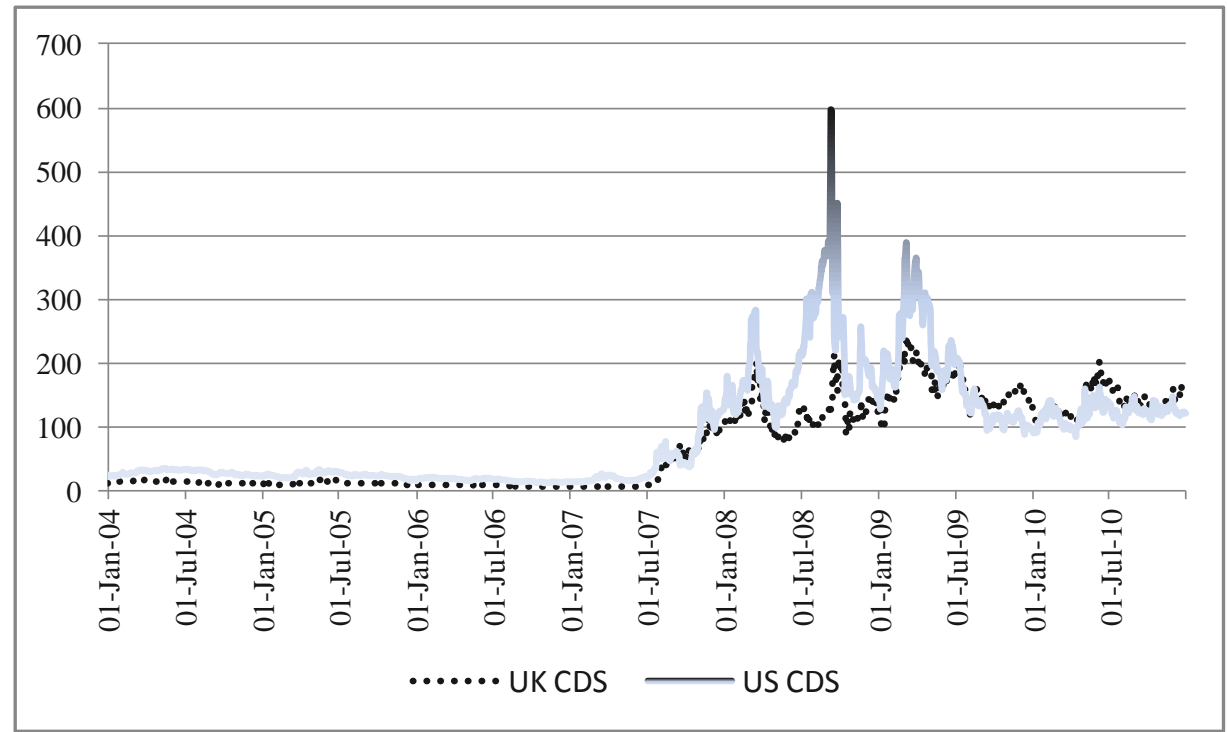

Figure 1: Basic Plot of CDS Indexes

The huge difference between the maximum and the minimum of the variables is clearly attributable to the financial crisis period starting in 2007. It may also indicate heavy tailed distribution. The basic profile of the graphs tends to indicate high correlations between these the CDS markets as well. The following Table 2 gives the correlation measures of these two CDS indexes. 
Table 2:Correlation Measures

\begin{tabular}{|c|c|c|c|}
\hline \multicolumn{4}{|c|}{ Correlation Measures } \\
\hline & Pearson Correlation & Kendall's Tau & Spearman's Rho \\
\hline UK - USA & $0.8539^{* * *}$ & $0.7664^{* * *}$ & $0.9230^{* * * *}$ \\
\hline \multicolumn{4}{|c|}{$\begin{array}{l}\text { Pearson correlation is a linear-based measurement of dependence. The nonparametric rank correlations, } \\
\text { Kendall's tau and Spearman's rho, are useful for the observations in the tails. Moreover, Kendall's tau and } \\
\text { Spearman's rho are associated with copula functions (not studied here). } 1 \% \text { level of significance is indicated } \\
\text { by }{ }^{* * *} \text {. }\end{array}$} \\
\hline
\end{tabular}

All the correlation measures are positive indicating that the increase US CDS premium is associated with an increase in the UK CDS premium. The Kendall tau is significantly positive, showing that the probability of concordance is significantly higher than the probability of discordance. The Spearman rho is also significantly positive, indicating obvious rank correlations. The values of Kendall's tau and Spearman's rho are consistent with each other and the linear correlation.

Table 3:Convergence in CDS Indexes (UK and USA)

Test of Convergence in CDS Indexes (UK and USA)

\begin{tabular}{ccccc}
\hline Relevant t-Stat. & $\mathrm{d}_{\text {SS }}$ & $\overline{\mathrm{b}}$ & $\mathrm{a}_{1}$ & $\sigma_{\eta}^{2}$ \\
$-46.16^{* * *}$ & $0.34896^{* * *}$ & $0.99301^{* * *}$ & -0.11562 & $0.00336^{* * *}$ \\
& $(0.06110)$ & $(0.00348)$ & $(0.12493)$ & $(0.00064)$ \\
\hline
\end{tabular}

Relevant t-statistic $\mathrm{t}(\widehat{\phi})=(\widehat{\phi}-1) / \sqrt{\mathrm{h}_{\phi}^{-1}}$ is described in the text. Asterisk indicates the hypothesis of No Interconnectedness is rejected at the $1 \%$ level of significance. Critical values are obtained from St. Aubyn (1999).

Other parameters relate to steady state property of convergence as described in the text. The numbers in the parentheses below the parameters are the appropriate standard errors.

The steady state coefficient $\mathrm{d}_{\mathrm{SS}}$ is derived as a difference between the US banking sector CDS premium and that of the UK banking sector. The coefficient is positive and significant implying that the aggregate premium charged for the US banking sector is higher than that of UK. This is consistent with the plot in Figure $1 . a_{1}$ is the short-run speed of convergence of the banking sector CDS premium between these two countries and it is not statistically significant. It is also evident from the results in Table 3 that the variance $\sigma_{\eta}^{2}$ is significant, which implies that the speed of convergence or interconnectedness for the two CDS premium series is time 
varying. The parameter representing the long-run value of the time-varying speed of convergence $\overline{\mathrm{b}}$, is significant though. It is slightly lower than 1 and this implies that the difference between the banking sector CDS premium eventually will converge to the steady state value given by $\mathrm{d}_{\mathrm{SS}}$. This is an interesting finding despite the jump in the CDS premium during the period of financial crisis in each country.

In summary, there is no statistically significant evidence of short-run time-varying banking sector interconnectedness between the two markets, the steady state long term interconnectedness is evident. The presence of interconnectedness may be reflective of the common sector response to government intervention programs in the wake of the financial crisis. Similar to the US, the UK government intervened quickly with financial institutions bailouts, guaranteed bank deposits, stimulus packages encouraging consumer spending and investments in infrastructure projects. This longer term steady state interconnectedness of the two markets might indicate greater operational and structural alignment of financial institutions operating in these countries and similarity in investor behaviour and broader market conditions. Besides, many of the large banking institutions operate in both these countries and would have similar regulatory expectations.

Sheard (2009) argues that an important transmission channel of policy is its effect on private sector beliefs and expectations about the future. In banking crises, depressions or deflations, economies can be viewed as suffering from a coordination failure, which might have strong negative effects on consumer and business confidence and market sentiment. Governments and central banks need to show a strong and timely commitment to achieving their policy goals and then take forceful action consistent with those goals. Along these lines, the International Monetary Fund attributes the improved financial conditions of late across the globe to 'cuts in policy interest rates, continued provision of ample liquidity, credit easing, public guarantees, and bank recapitalization which have appreciably lowered concerns about systemic failure and have supported intermediation' (IMF, 2009).

Figure 2 depicts the consumer sentiment index in the two countries covering the period of financial crisis. As expected, both the markets show fall in the sentiment index roughly coinciding with the period of financial crisis. Although, the UK market show bigger drop in sentiment, its pick up tends to match with that of the US. In line with the remarks above, it appears that the policymakers in both these countries are successful, most of the time, in communicating a timely and committed approach to responding to the financial crisis. Most importantly, the US policymakers have said that they will do "whatever it takes" to overcome the current problems, which has sent a strong message to the national and international public, backed up with consistent policy action. 


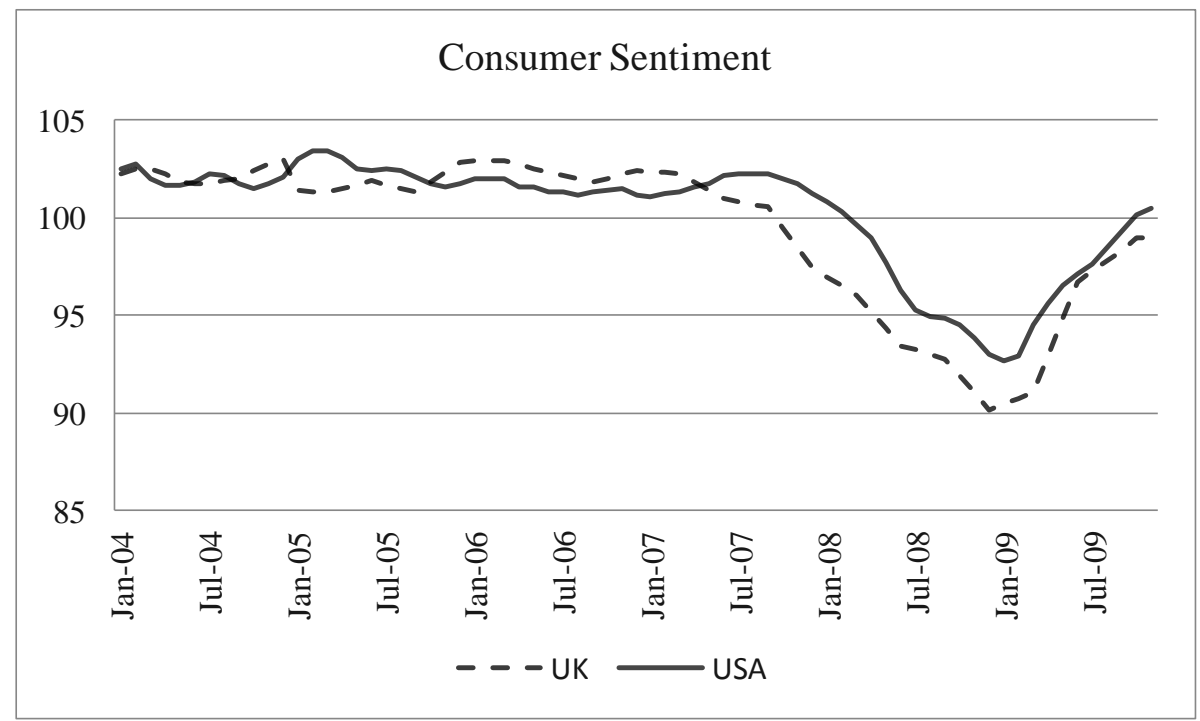

Figure 2: Consumer Sentiment (January 2004 - December 2009)

\section{Conclusion}

The notion of interconnectedness of two markets is important in the context of analysing the effects of policy responses, particularly in times of crisis. The recent global financial crisis gives us an opportunity to examine how two major markets with significant banking sectors fared when the respective central banks intervened.

We find that the measure of convergence using the Kalman filter tests indicate that there is lack of support for short-run time-varying banking sector interconnectedness between the two markets in the US and in the UK. But, there is definitely steady state long term interconnectedness between these two markets. This may be reflective of the common sector response to government intervention programs in the wake of the financial crisis. Both historically and in recent times there is some commonality in the banking sector regulations in these two markets. This is probably the convergence tests are highlighting. Based on these findings we conclude that coordinated global financial regulatory policy with discretionary allocation of interventionary funds and execution strategy at a national level is the preferred financial markets' regulatory structure going forward.

As part of the ongoing research, it would be useful to focus on other industries and the relevant aggregate CDS data. 


\section{References}

[1] Alexopoulou, I., Andersson, M. and Georgescu, O. M. (2009), An Empirical Study on the Decoupling Movements between Corporate Bond and CDS Spreads, Working Paper Series No. 1085, August, European Central Bank.

[2] Ashcraft, A. B. and Santos, J. A. C. (2009) Has the CDS market lowered the cost of corporate debt? Journal of Monetary Economics 56, pp. 514-523.

[3] Barro, R. and Sala-i-Martin, X. (1995), Economic growth, McGraw-Hill, NewYork.

[4] Bernard, A. B. and Durlauf, S. N. (1995), Convergence in international output, Journal of Applied Econometrics, 10, pp. 97-108.

[5] Bhar, R., Chiarella, C., Runggaldier,W., (2004), Inferring the forward-looking equity risk premium from derivative prices. Studies in Nonlinear Dynamic Econometrics, Vol. B: No.1, Article 3.

[6] Bhar, R. and Hamori, S. (2005), Empirical Techniques in Finance, Springer, Heidelberg.

[7] Bolton, P. and Oehmke, M. (2011), Credit default swaps and empty creditor problem, Review of Financial Studies, Available online February 12, 2011.

[8] Chan-Lau, J. A., Mitra, S. and Ong, L. L. (2007), Contagion Risk in the International Banking System and Implications for London as a Global Financial Center, IMF Working Paper (WP/07/74).

[9] Durlauf, S. Johnson, P. (1992), Local vs. global convergence across national economies, NBER working paper no. 3996, Cambridge, Massachusetts.

[10] Ericsson, J., Reneby, J. and Wang, H. (2006), Can structural models price default risk? Evidence from bond and credit derivative markets, Working paper, McGill, http://w4.stern.nyu.edu/salomon/docs/Credit2006/EricssonRenebyWang.pdf.

[11] Greatrex, C. (2008), The credit default swaps market's determinants, efficiency and relationship to the stock market, Paper AAI3301438, ETD Collection for Fordham University. Available at: http://fordham.bepress.com/dissertations/AAI3301438.

[12] Hall, S., Robertson, D. and Wickens, M. (1992), Measuring convergence of the EC economies. Manchester School of Economics and Social Studies, 60, Supplement: 99-111.

[13] Jochum, C., (1999), Volatility spillovers and the price of risk: evidence from the Swiss stock market. Empirical Economics Vol. 24, 303-322.

[14] MacKinnon, J. G. (1991), Critical values for cointegration tests, in: Engle, Granger (eds.), pp. 267-276.

[15] Malliaris, A.G., Urrutia, J. L. (1992), The international crash of October 1987: causality tests. Journal of Financial Quantitative Analysis 27, 353-364.

[16] Malliaris, A.G., Urrutia, J. L. (1997), Equity and oil markets under external shocks. In: Ghosh, D., Ortiz, E. (Eds.), Global Structure of Financial Markets. Routledge Publishers, London, pp. 103-116.

[17] McCarthy, J. and Najand, M. (1995), State space modelling of linkages among international markets. J. Multinational Finance Managemeny 5, 1-9.

[18] Merton, R. (1980), On estimating the expected return on the market. Journal of Financial Economics Vol. 8, 323-361.

[19] Nanto, D.K. (2009), The global financial crisis: Analysis and policy implications, Congressional Research Service, October 2, 2009. 
[20] Norden, L. and Weber, M. (2004), The Co-movement of Credit Default Swap, Bond and Stock Markets: an empirical Analysis, European Financial Management, 15(3), pp. 529 562.

[21] Quah, D. (1996), Empirics for economic growth and convergence, European Economic Review, 40 (6), pp.1353-1375.

[22] Sheard, P. (2009), Japan and the global financial crisis, A Journal of the East Asean Foundation, Vol.4, No 1 Spring 2009.

[23] St. Aubyn, M. (1995), Evaluating tests for convergence of economic series using Monte Carlo methods with an application on real GDPs per head, Unpublished PhD thesis, London Business School.

[24] St. Aubyn, M. (1999), Convergence across industrialized countries (1890-1989): new results using time series methods, Empirical Economics, 24, pp. 23-44.

[25] Stulz, R. (2010), Credit default swaps and the credit crisis, Journal of Economic Perspectives, 24(1), pp. 73-92.

Received March 15, 2015; accepted November 10, 2015.

Ramaprasad Bhar Ph.D

School of Rick and Actuarial Studies,

The University of New South Wales, Australia.

Tel: +612-9385-4930

r.bhar@unsw.edu.au 